\title{
Optimization of an Experimental Hybrid Microgrid Operation: Reliability and Economic Issues
}

\author{
Aitor Milo, Haizea Gaztañaga, Member IEEE, Ion Etxeberria-Otadui, Member IEEE, Endika Bilbao, \\ Pedro Rodríguez, Member IEEE
}

\begin{abstract}
In this paper a hybrid microgrid system, composed of RES (Renewable Energy System) and CHP (Combined Heat and Power) systems together with a battery based storage system is presented. The microgrid is accompanied by a centralized energy management system (CEMS) in order to optimize the microgrid operation both in grid-connected and in stand-alone modes. In grid-connected mode the optimization of the economic exploitation of the microgrid is privileged by applying optimization techniques. In stand-alone mode, management functions are applied to improve the reliability of the facility by means of islanding operation capability. The optimization analysis has been carried out in simulation while the reliability improvement of the microgrid operation has been analyzed in simulation and proven experimentally.
\end{abstract}

Keywords-Hybrid microgrid, RES, CHP, grid connected, standalone, storage, optimization.

\section{INTRODUCTION}

Tn the last years the number of Distributed Generation (DG) 1 systems connected to the grid has considerably increased and it is expected that this evolution will continue and even grow in the near future. Deregulation of the electric utility industry, environmental concerns and rapid technological developments of DG systems are considered to be the main causes of this proliferation. Nevertheless, as the number of DG facilities increases their impact on the grid operation can not be regarded as negligible any more.

This work was supported in part by the Spanish Ministerio de Ciencia e Innovación under Contract ENE2008-06841-C02-02/ALT in the context of the Research Project FOTOPROINT, "Topologías avanzadas de procesadores de potencia fotovoltaicos con altas prestaciones de calidad y eficiencia".

A.Milo, H.Gaztañaga, I.Etxeberria-Otadui, E.Bilbao are with IKERLAN-IK4 Technological Center, E-20.500 Mondragón, Spain (e-mail: amilo@ikerlan.es; hgaztanaga@ikerlan.es, ietxeberria@ikerlan.es, ebilbao@ikerlan.es), Pedro Rodríguez is with Universitat Politècnica de Catalunya, 0822 TerrassaBarcelona, Spain (e-mail prodriguez@ee.upc.edu).
The microgrid concept is an interesting solution to improve the integration of DG systems into the grid. A microgrid can be defined as a group of generators and loads connected to the grid in a single point that accompanied with different control levels can be seen as a controllable load or generator from the grid. In addition to that, it can operate both in grid-connected and in stand-alone mode [1].

Concerning DG technologies, at the moment there exist two types of systems with a significant presence in the network: Renewable Energy Sources (RES) and Combined Heat and Power (CHP) facilities. RES systems are characterized by their environmentally friendly nature while the main advantage of CHP systems is their programmable nature and high efficiency. In fact they can be dispatched privileging their electrical or their thermal production depending on the demand. Even though both systems have advantages, DG systems have certain limitations from the control point of view for their integration in a microgrid. On the one hand, RES systems have an intermitent nature since their output power depends on the availability of the primary source (wind, sun, etc.). On the other hand, CHP systems can be limited by their insufficient dynamic performances for load tracking. These two limitations can be exceeded by the introduction of an adequate storage based support system and by their grouping in centralized controlled microgrids [2].

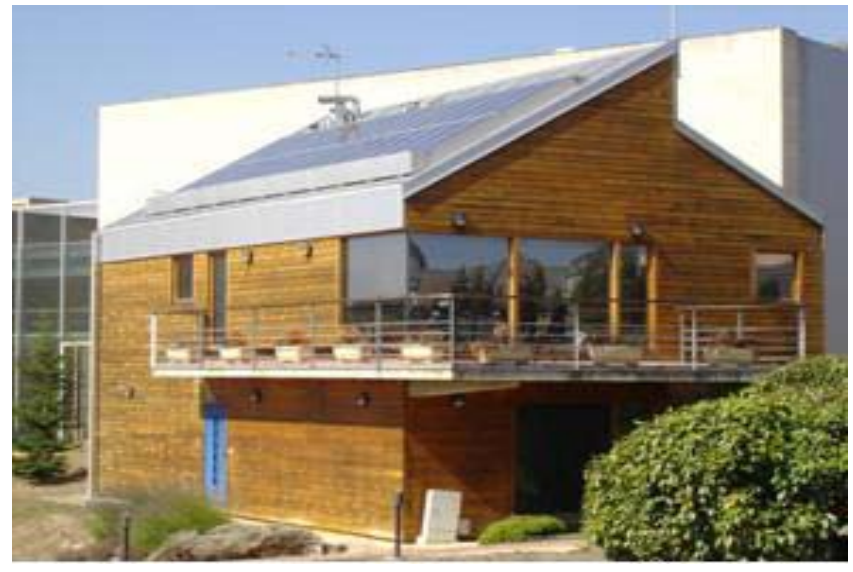

Fig. 1. Picture of the home applications laboratory. 
In this paper an experimental hybrid microgrid system (see Figure 1), composed of RES and CHP systems together with a battery based support system is presented. The microgrid is accompanied by a centralized energy management system (CEMS) in order to optimize the microgrid operation both in grid-connected and in stand-alone modes and its transitions between operating modes. The optimization objective is different in each mode. In grid-connected mode the optimization of the economic exploitation of the microgrid is privileged by applying optimization techniques. In stand-alone mode, management functions are applied to improve the reliability of the facility by means of islanding operation capability.

The objective of this paper is to analyze the optimization techniques and management functions to be implemented in the CEMS (centralized energy management system). The optimization analysis has been carried out in simulation while the reliability improvement of the microgrid has been analyzed in simulation and proven experimentally.

\section{HYBRID MICROGRID SYSTEM DESCRIPTION}

The analyzed system is an experimental hybrid microgrid facility installed at the home applications laboratory (Domolab) of IKERLAN-IK4 technological research center (Spain). It comprises a photovoltaic system as a RES (Renewable Energy System), a microturbine and a Stirling engine as CHP (Combined Heat and Power) systems, a battery based support system as an electrical storage system, a gas boiler and local electrical and thermal loads. Figure 2 illustrates the schematic distribution of the hybrid microgrid system of IKERLAN-IK4.

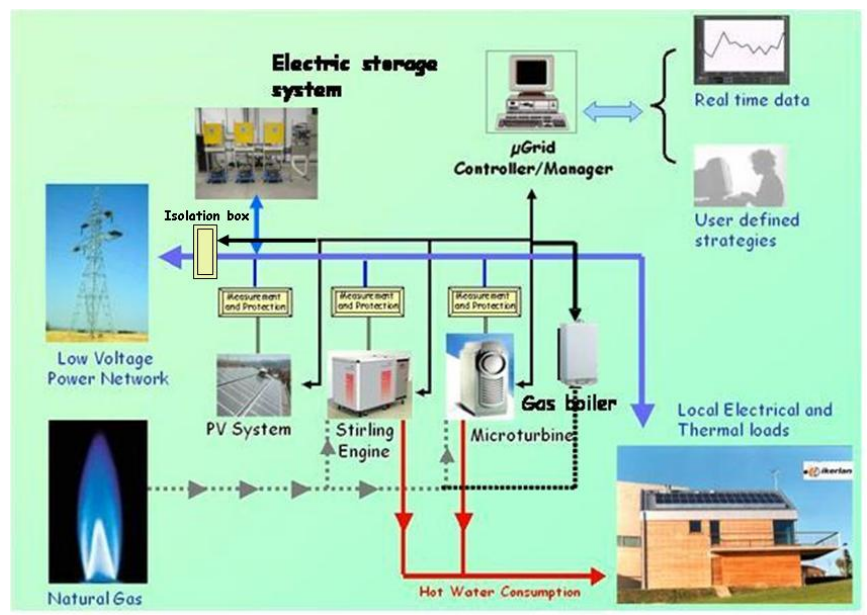

Fig. 2. Experimental hybrid microgrid schematic distribution.

Considered generation and consumption characteristics of generators and loads are presented in Table I.

Unlike in a decentralized topology [3] where an intelligent energy control in each DG unit is required, in a centralized controlled microgrid the energy management strategies are concentrated in a unique system. A centralized controlled microgrid allows the integration of any commercial DG unit, even if they have no energy management strategies implemented locally, which is the case in the considered microgrid.

Therefore the CEMS is the responsible for the control of the different generation units and loads in order to assure the desired performances both in grid-connected and in standalone modes. The CEMS is based on two main strategies. Each strategy is associated with an operating mode of the system, grid connected mode and stand-alone mode and each operating mode has a particular optimization objetive.

In grid-connected mode the optimization of the economic exploitation of the microgrid is privileged by applying optimization techniques. In this case, thermal energy requirements are satisfied using the residual heat produced by the generation units, while the generated electrical power is consumed by local loads or injected into the grid.

In stand-alone mode, the objective of the CEMS is to increase the reliability of the facility in case of a blackout, avoiding interruptions and their related costs.

TABLE I:

CHARACTERISTICS OF GENERATION AND CONSUMPTION SYSTEMS

\begin{tabular}{|c|c|c|}
\hline System & Output power & Other aspects \\
\hline $\begin{array}{c}\text { Photovoltaic system } \\
\text { (Fagor Automation FSI 2.5) }\end{array}$ & $2 \mathrm{~kW}$ & -- \\
\hline Micro-turbine (Capstone C30) & $\begin{array}{l}\text { 30kWe and } \\
85 \mathrm{kWt}\end{array}$ & $\begin{array}{l}85 \% \text { efficiency } \\
\text { Natural gas } \\
\text { burning }\end{array}$ \\
\hline Stirling engine (SOLO stirling) & $\begin{array}{c}9,5 \mathrm{kWe} \text { and } 26 \\
\mathrm{kWt}\end{array}$ & $\begin{array}{l}85 \% \text { efficiency } \\
\text { Natural gas } \\
\text { burning }\end{array}$ \\
\hline Gas boiler (Fagor) & $30 \mathrm{kWt}$ & $90 \%$ efficiency \\
\hline $\begin{array}{c}\text { Electrical energy storage } \\
\text { support system(Sunny Island of } \\
\text { SMA) }\end{array}$ & $\begin{array}{l}3 \text { monophase } \\
\text { inverters, } \\
4.8 \mathrm{kWh} \text { energy } \\
\text { with } 3.6 \mathrm{~kW} \\
\text { nominal power }\end{array}$ & $\begin{array}{l}\text { Based on } \mathrm{PbA} \\
\text { batteries }\end{array}$ \\
\hline Domestic loads & $\begin{array}{l}\text { Critical load: } \\
12 \mathrm{kWe} \text { and } \\
64 \mathrm{kWt}\end{array}$ & $\begin{array}{l}\text { Conventionnal } \\
\text { domestic } \\
\text { appliances }\end{array}$ \\
\hline
\end{tabular}

III. GRID-CONNECTED MODE: APPLICATION OF OPTIMIZATION TECHNIQUES TO REDUCE COSTS

In this operating mode the microgrid operates connected to the public low voltage grid and the electrical load supply is guaranteed in all time by the grid.

In this case the objective of the CEMS is to optimize the energy cost of the microgrid by applying optimization techniques [4]. The CEMS calculates the appropriate generation references for the generation units in order to reduce generation costs and optimize the economic exploitation of the facility. 


\section{A - Problem analysis}

The microgrid energy cost optimization algorithm developed for this strategy has been analyzed as a linear optimization mono-objective problem with constraint functions. Each generation unit has been characterized with a series of parameters that define them energetically and economically. Among these parameters, the maintenance cost, emissions cost, efficiency, maximum power generation level, and gas and electricity price are considered.

\section{$B$ - Problem formulation}

The objective function is defined as the sum of the cost functions of all the generation units including the supply cost of the main grid. The optimization objetive is to minimize the total supply cost of the electric and thermal load demand, as it is stated in (1).

$$
\begin{aligned}
\text { Min. } & f_{\text {objetive }}\left(f_{\text {microturbine }}\left(A, \eta_{m c}, x_{m c}\right)+\right. \\
& f_{\text {Stirling engine }}\left(B, \eta_{s}, x_{s}\right)+ \\
& f_{P V \text { System }}\left(C, \eta_{P V}, P_{P V}\right)+ \\
& f_{\text {electrical grid }}\left(D, \eta_{\text {grid }}, x_{\text {grid }}\right)+ \\
& \left.f_{\text {Gas boiler }}\left(E, \eta_{\text {boiler }}, x_{\text {boiler }}\right)\right)
\end{aligned}
$$

where,

$f_{\text {microturbine }}, f_{\text {Stirling engine }}, f_{P V \text { System }}, f_{\text {Gasboiler }}, f_{\text {electrical grid }}$ are the micro-turbine, Stirling engine, photovoltaic system, gas bolier and main grid cost functions.

and,

$$
\begin{gathered}
A=\left(\begin{array}{c}
a_{1} \\
a_{2} \\
a_{3} \\
\cdot \\
\dot{a}_{n}
\end{array}\right) \quad(2) \quad B=\left(\begin{array}{c}
b_{1} \\
b_{2} \\
b_{3} \\
\cdot \\
\dot{b_{n}}
\end{array}\right) \quad(3) \quad C=\left(\begin{array}{c}
c_{1} \\
c_{2} \\
c_{3} \\
\dot{c_{n}}
\end{array}\right) \\
D=\left(\begin{array}{l}
d_{1} \\
d_{2} \\
d_{3} \\
\dot{d}_{n}
\end{array}\right) \quad \text { (5) } E=\left(\begin{array}{c}
e_{1} \\
e_{2} \\
e_{3} \\
\dot{e_{n}}
\end{array}\right) \quad(6)
\end{gathered}
$$

where,

$a_{1}, a_{2}, a_{3}, \ldots . ., a_{n}$ are the micro-turbine cost parameters $(€ / \mathrm{kW})$ $b_{1}, b_{2}, b_{3}, \ldots \ldots, b_{n}$ are the stirling engine cost parameters $(€ / \mathrm{kW})$ $c_{1}, c_{2}, c_{3}, \ldots . ., c_{n}$ are the photovoltaic sytem cost parameters $(€ / \mathrm{kW})$

$d_{1}, d_{2}, d_{3}, \ldots . ., d_{n}$ are the main grid cost parameters $(€ / \mathrm{kW})$

$e_{1}, e_{2}, e_{3}, \ldots . ., e_{n}$ are the gas bolier cost parameters $(€ / \mathrm{kW})$

Cost parameter are composed by fuel price, electricity price, operation \& maintenance cost, installation cost and equipment life-time.

$\eta_{m c}$ is the micro-turbine efficiency curve

$\eta_{S}$ is the Stirling engine efficiency curve

$\eta_{P V}$ is the photovoltaic system efficiency curve $\eta_{\text {grid }}$ is the main grid efficiency curve

$\eta_{\text {bolier }}$ is the gas boiler efficiency curve

$x_{m c}, x_{s}, x_{b o i l e r}$ are the micro-turbine, Stirling engine and gas boiler references $(\%)$

$x_{\text {grid }}$ is the power to be consumed from the main grid (kW)

$P_{P V}$ is the power generated by the photovoltaic system $(\mathrm{kW})$.

The main constraint functions for the optimization problem in this strategy may be summarized as follow:

- The maximum possible power should be taken from the photovoltaic system (RES).

- The amount of generated heat must be equal to the heat demand:

$$
P_{\text {total generated thermal }}=P_{\text {thermal demand }}
$$

- The amount of power (including grid power) should be equal or larger than the power demand:

$$
P_{\text {total generated electrical }} \geq P_{\text {electrical demand }}
$$

\section{C-Simulation results}

The following figures show the power references of the microturbine and the Stirling engine respectively as well as the amount of power consumed by the main grid and the natural gas consumption of the gas boiler, considering a $2 \mathrm{kWe}$ photovoltaic generation, depending on the power and heat demand.

It can be observed in Figures 3 and 4 that the microturbine and the Stirling engine power references have a pyramidal surface shape. Figures 5 and 6 show that for low electric and thermal demand is best to consume electricity from the main grid and to generate thermal energy using the gas boiler. In consequence, when the heat demand is low the CEMS gives priority to the supply of the demand by the main grid and the gas boiler. As heat demand increases the use of CHP generation units becomes more efficient. Therefore, a scenario with high thermal and electric demand and low demand variations is the best for micro-cogeneration operation.

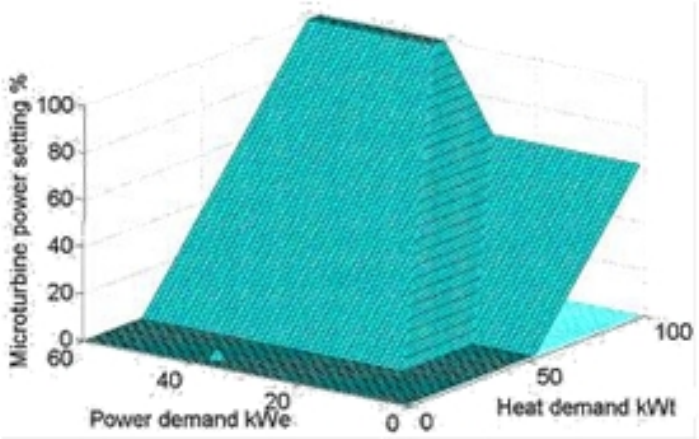

Figure 3. Micro-turbine power setting $\%$ with different level of heat and power demand. 


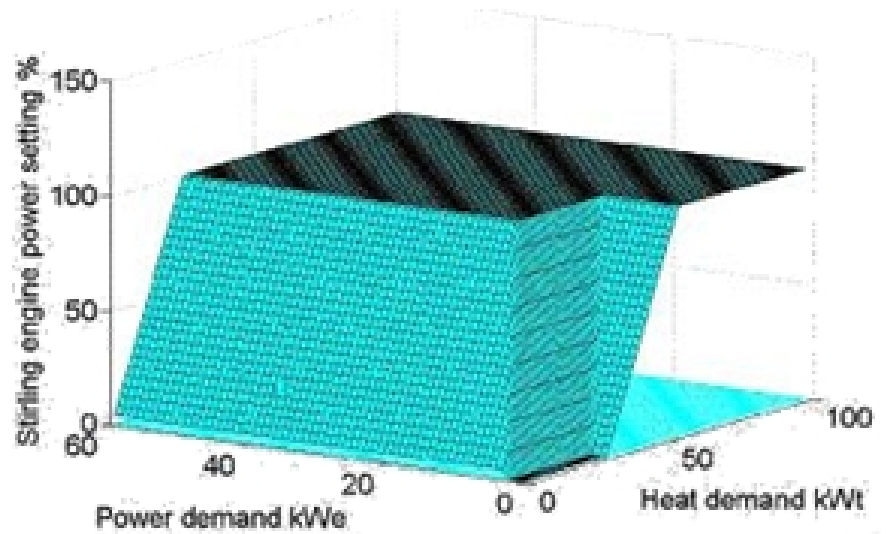

Figure 4. Stirling engine power setting \% with different level of heat and power demand.

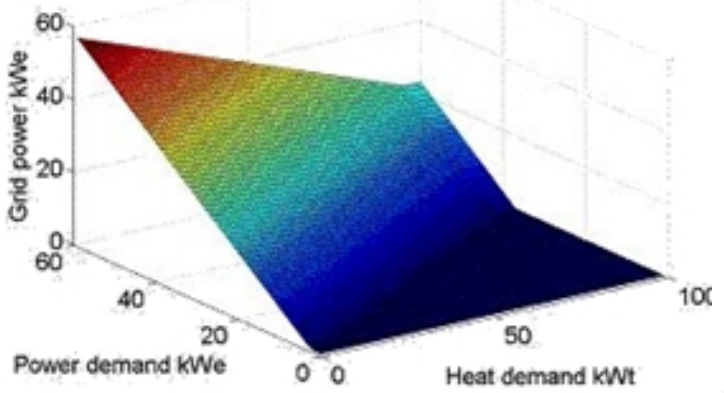

Figure 5. Consumption from the main grid $(\mathrm{kW})$ with different level of heat and power demand.

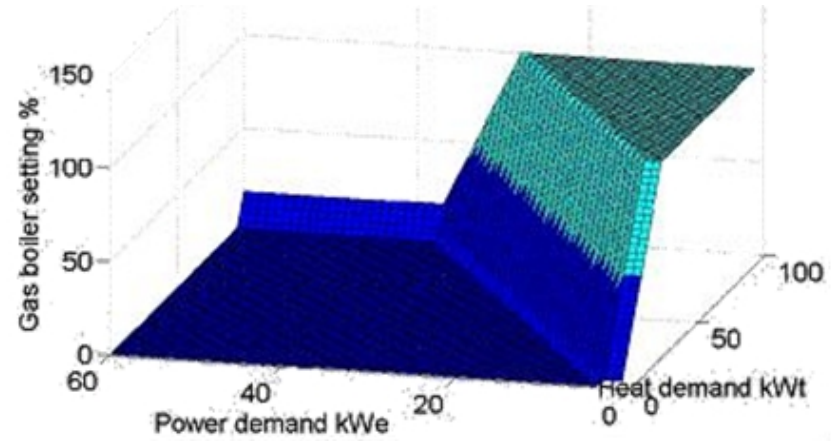

Figure 6. Gas boiler setting (\%) with different level of heat and power demand.

\section{STAND ALONE MODE: ISLANDING OPERATION CAPABILITY IMPROVEMENT}

In stand-alone mode mode, due to the unavailability of the public low voltage grid, two requirements must be fulfilled: the power balance between the generation and the consumption and the control of the main parameters of the facility (voltage amplitude and frequency).

\section{A-Microgrid management in stand-alone mode}

In this case the objetive of the CEMS is to increase the microgrid reliability by assuring local load supply. Since CHP generators have a controllable nature, the CEMS calculates their electrical power references in order to track local load variations. In consequence their electrical generation is privileged and the thermal demand supply is not assured. Due to the dynamic limitations of CHP systems (loads dynamics are higher than CHP response dynamics) the storage based support system is responsible for assuring the power balance of the facility by means of absorbing and injecting the power deviation between the RES and CHP generation units and the local load. The support system is voltage controlled in droop mode [5] and it regulates the main parameters of the system.

The objetive function is defined as:

$$
\begin{aligned}
\text { Min. } & f_{\text {objetive }}\left(f_{\text {microturbine }}\left(A, \eta_{m c}, x_{m c}\right)+\right. \\
& f_{\text {PV System }}\left(C, \eta_{P V}, P_{P V}\right)+ \\
& f_{\text {Stirling engine }}\left(B, \eta_{s}, x_{s}\right)+ \\
& \left.f_{\text {Gasboiler }}\left(E, \eta_{\text {boiler }}, x_{\text {boiler }}\right)\right)
\end{aligned}
$$

The main constraint functions for the optimization problem in this operating mode are summarized as follows:

- The maximum possible power should be taken from the photovoltaic system.

- The steady-state total electrical demand should be met by the photovoltaic system, the Stirling engine and the micro-turbine:

$$
P_{\text {microturbine }}+P_{P V}+P_{\text {stirling }}=P_{\text {electrical demand }}
$$

\section{$B$ - Microgrid management in the transitions between} operating modes

In the following section the management functions to be implemented in the CEMS to assure the desired performances and functionalities in the transitions between operating modes are analyzed.

\section{B.1 - Transition from Grid-Connected to Stand-Alone Mode}

Disconnection of the microgrid from the grid can be provoked by many causes, like unsatisfactory grid voltage (in terms of amplitude or waveform) or even economic aspects related to power price.

In order to monitor grid voltage characteristics a Voltage Monitoring Module is required. This module measures continuously the rms grid voltage comparing it with a preestablished threshold value. When any of the phase voltages decreases below the threshold value during a pre-established period, the detection signal is activated and the microgrid is disconnected from the utility grid.

Microgrid power consumption is also continuously measured in order to detach non-critical loads in case of lack of locally generated power. In addition if consumption or generation conditions are modified and it becomes possible to feed all the local loads, non-critical loads will be reconnected.

\section{B.2 - Transition from Stand-Alone to Grid-Connected Mode}

If the grid-disconnection cause disappears and the gridvoltage fulfills the desired requirements, the transition from islanded to grid-connected mode can be started. The grid 
voltage conditions will be again monitored by the Voltage Monitoring Module. This way if the grid voltage exceeds the threshold value the detection signal is disabled. However, before the reconnection, the microgrid has to be synchronized with the grid voltage in order to avoid hard transients in the reconnection.

Once the voltage in the microgrid is synchronized with the utility voltage the microgrid can be reconnected to the grid. In the same way if non-critical loads are detached they are also reconnected.

The transition sequences between operation modes are summarized in Figure 7 [6].

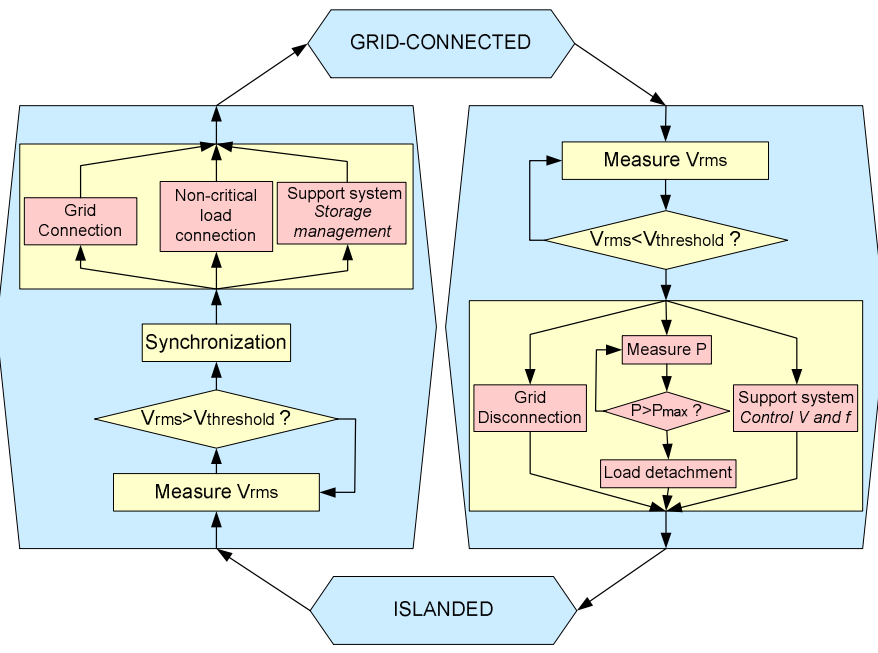

Figure 7. State diagram of the transitions from grid-connected mode to islanded mode and vice versa.

\section{C-Simulation results}

A simulation analysis has been carried out using PSCAD/EMTDC in order to test and validate the management functions implemented in the CEMS of the micogrid. The hybrid microgrid of IKERLAN-IK4 has been taken as case study. In the considered scenario a $3 \mathrm{kWe}$ load demand is supplied between the grid and the CHP $(2 \mathrm{kWe})$ in gridconnected mode and it is considered that there is no photovoltaic generation at this moment. CHP generation units have been modeled as ideal power sources considering the dynamics of the corresponding primary energy sources. Loads have been modelled as constant impedance loads and the support storage system by a voltage inverter connected to an ideal voltage source.

Figure 8 illustrates the evolution of the active power absorbed from the grid, the active power consumed by the loads, the active power generated by the CHPs and the active power generated by the support system. Initially the system is connected to the grid and absorbing $1 \mathrm{~kW}$ power from the grid to feed the load demand of $3 \mathrm{kWe}$. The CHP systems are generating $2 \mathrm{kWe}$ and the support system is in stand-by mode. At $\mathrm{t}=20 \mathrm{~s}$ a fault occurs in the utility grid and when the detection functions detects it the microgrid is disconnected from the grid. At the same moment the support system passes to be the responsible for the control of the main parameters of the system injecting the necessary power to maintain the power balance between the generation and the consumption.
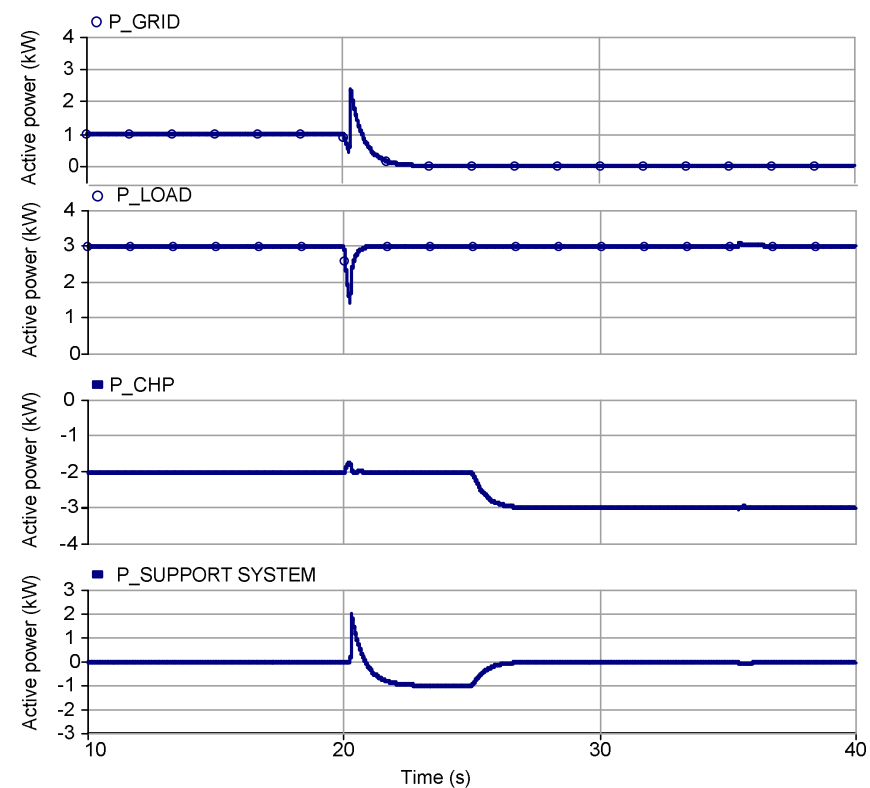

Figure 8. Grid, load, CHP and support system active power in the successive transitions between operation modes.

It can be observed that in stand-alone mode the CEMS adjusts CHPs' power reference to track the local load demand. The load supply is guaranteed by the support system while the CHPs' power reaches their references. Thus, the stability of the microgrid is assured and the reliability of the facility is improved.

\section{D- Experimental results}

In order to validate the simulation results experimental tests have been carried out in the real hybrid microgrid in very similar conditions and obtaining similar results.

Figure 9 shows a sequence where the operating mode of the microgrid transits from grid-connected to islanded mode. Initially the system is connected to the grid absorbing $3 \mathrm{kWe}$ to supply local loads and to charge the energy storage system of the support system. At $\mathrm{t}=12 \mathrm{~s}$ a fault occurs in the utility grid and the microgrid is disconnected from the grid. At this moment the support system replaces the grid by means of controlling the main parameters of the microgrid and guaranteeing the power balance between the generation and the consumption. The stability of the microgrid is assured by feeding the loads by the power extracted from the batteries. As soon as the CEMS detects that the microgrid is disconnected from the grid, it adjusts the microturbine power reference in order to track the load demand. As the microturbine power reference reaches its set-point, the support system power generation descreases. This operating mode guarantees the load supply at any time. 


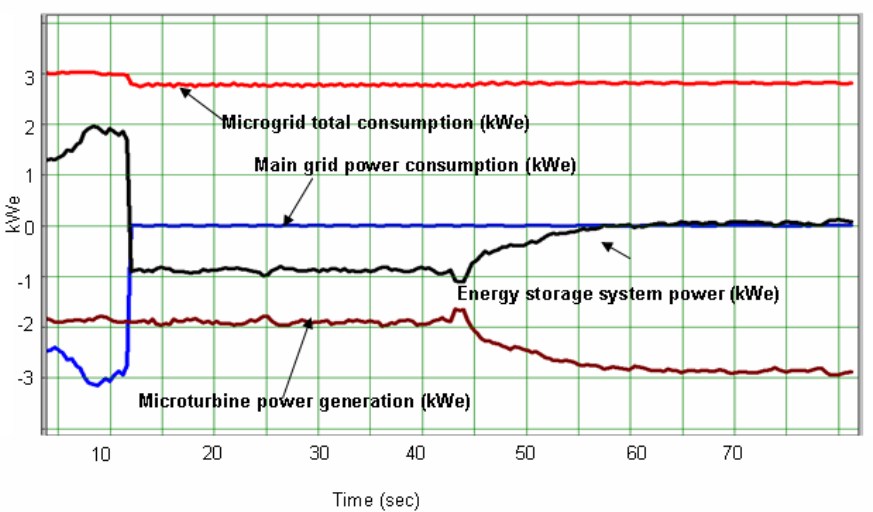

Figure 9. Measured active power injected to the grid $(\mathrm{kW})$, measured microturbine's active power $(\mathrm{kW})$, measured support system's active power $(\mathrm{kW})$ and local electrical load demand $(\mathrm{kWe})$.

In stand-alone mode, due to the droop mode control structure of the support system, the frecuency and the voltage of the microgrid present small variations from their nominal values. These variations depend on the droop curves implemented in the control structure. As it can be seen in Figure 10 the frecuency in the hybrid microgrid varies from 50 $\mathrm{Hz}$ to $49,5 \mathrm{~Hz}$. Concerning the voltage, its rms value decreases from 230V to 220Vas observed in Figure 11.

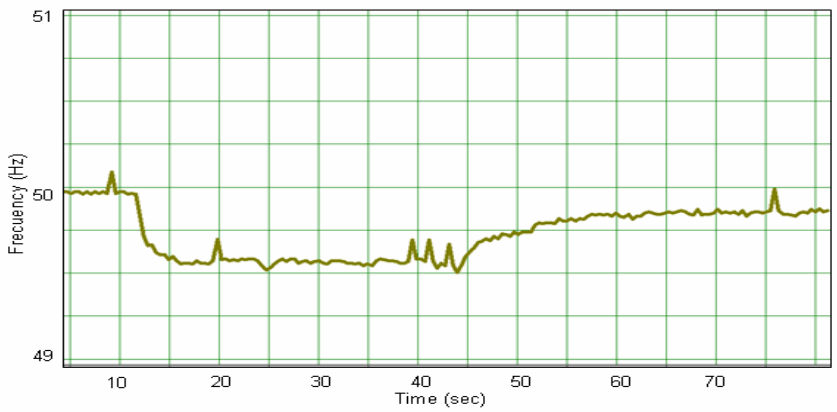

Figure 10. Measured frecuency variations in the hybrid microgrid (Hz).

The instantaneous voltage variation in the transitions between grid-connected to stand-alone mode is depicted in Figure 12. As it can be observed the variation occurs without important deviations.

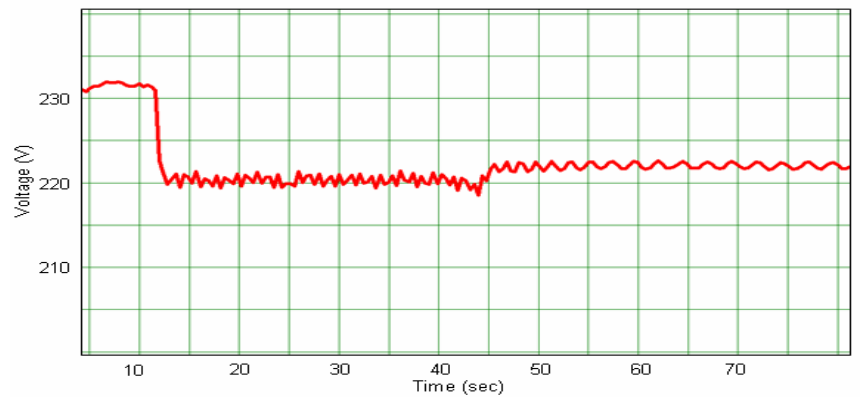

Figure 11. Measured rms voltage variation in the hybrid microgrid (V).

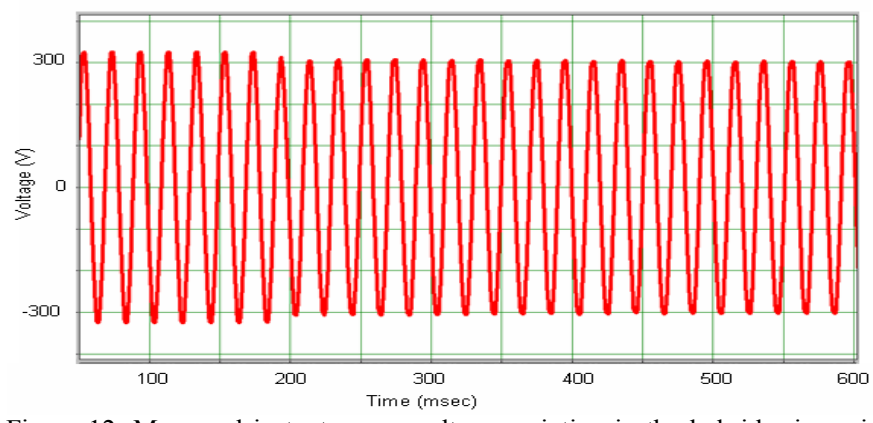

Figure 12. Measured instantaneous voltage variation in the hybrid microgrid (V).

\section{CONCLUSION}

In this paper a hybrid microgrid system installed at the IKERLAN-IK4 technological research center, has been presented as an interesting structure to improve RES and CHP system integration into the grid. The microgrid includes a battery based support system and a centralized energy management system (CEMS) in order to overcome RES and CHP limitations and optimize the microgrid operation both in grid-connected and in stand-alone mode. The optimization techniques and management functions implemented in the CEMS are aimed to optimizing the economic exploitation of the microgrid in grid-connected mode and improving the reliability of the installation by means of islanding operation capability. It has been shown through simulation analysis and experimental tests that the hybrid microgrid presents successful performances in both operation modes (gridconnected and stand-alone) as well as in the transitions between them.

\section{REFERENCES}

[1] Lasseter R.H. "MicroGrids". Power Engineering Society. Winter Meeting. IEEE 2002. Vol. 1, 27-31 Janvier 2002

[2] A. Tsikalakis, N. Hatziargyriou, "Centralized Control for Optimizing Microgrids Operation", IEEE Transactions On energy Conversion, Vol. 23, $\mathrm{N}^{\mathrm{o}}$ 1, pp 241-248, March 2008.

[3] S.J.Chatzivasiliadis, N.D. Hatziargyriou, A.L.Dimeas, "Development of an Agent Based Intelligent Control System for Microgrids", Power and Energy Society General Meeting - Conversion and Delivery of Electrical Energy in the 21 ${ }^{\text {st }}$ Century, IEEE, pp 1-6, July 2008.

[4] M. Chaudry, J. Ekanayade, N. Jeckins, "Optimum control strategy for $\mu$ CHP Unit”, International Journal of Distributed Resources, Vol 4, $\mathrm{N}^{\circ}$ 4, pp 265-280, February 2008.

[5] D. Georgakis, S. Papathanassiou, N. Hatziargyriou, A. Engler, Ch. Hardt, "Operation of a prototype Microgrid system based on microsources equipped with fast-acting power electronics interfaces", Conf. PESC'04, Aachen, Alemagne, ISBN 0-7803-8399-0.

[6] H. Gaztañaga, I. Etxeberria-Otadui, S. Bacha, D. Roye, "Real-Time Analysis of the Control Structure and management Fucntions of a Hybrid Microgrid system", Conf. IECON'06 Conference, Paris, France. 